\title{
Personal Protective Equipment during Endoscopy
}

\author{
Shibi Mathew ${ }^{1^{*}} \quad$ Mathew Philip ${ }^{1^{*}}$ \\ ${ }^{1}$ Lisie Institute of Gastroenterology, Lisie Hospital, Kochi, \\ Kerala, India
}

\begin{abstract}
Address for correspondence Mathew Philip, MD, DM, Lisie Institute of Gastroenterology, Lisie Hospital, Kochi 682018, Kerala, India (e-mail: drmathewphilip@gmail.com).
\end{abstract}

\begin{abstract}
Keywords

- COVID-19

- PPE

- endoscopy

The novel coronavirus disease 2019 (COVID-19) which originated in China has been declared a pandemic by the World Health Organization (WHO). This virus gets transmitted through air droplets and direct contact. Health care workers doing aerosolgenerating procedures are at a higher risk of acquiring the infection. Many procedures done by the gastrointestinal endoscopists are classified as aerosol-generating procedures, which in turn underline the need for proper safety precautions during these procedures. Apart from general safety measures advised by various organizations, proper use of personal protective equipment (PPE) is a pivotal factor in safeguarding health care personnel during endoscopy. This article provides a short overview of the different PPEs available and their proper use in endoscopy.
\end{abstract}

\section{Introduction}

The novel coronavirus disease 2019 (COVID-19) caused by severe acute respiratory syndrome coronavirus 2 (SARSCOV-2) was first reported from Wuhan, the capital of Hubei Province of China in December 2019. Since then, the infection has spread to many countries around the world. On March 11, 2020, the World Health Organization (WHO) has declared the COVID-19 outbreak as a pandemic.

The common presenting symptoms of COVID-19 include fever, cough, and shortness of breath. ${ }^{1}$ Gastrointestinal (GI) symptoms like anorexia, nausea, vomiting, abdominal pain, and/or diarrhea can occur early and are associated with poor clinical outcomes. The median incubation period is approximately 5.5 days and ranges from 0 to 14 days. Reports from China and Italy have shown asymptomatic or milder disease in approximately $80 \%$ of patients. Human-to-human transmission occurs during close contact or through air droplets generated during coughing, sneezing, or talking.

The risk of COVID-19 infection among health care workers is significant as documented from one of the initial studies from Wuhan, which showed a $29 \%$ infection rate among health care workers. ${ }^{2}$ Upper GI endoscopic procedures like esophagogastroduodenoscopy, small bowel enteroscopy, endoscopic ultrasound (EUS), endoscopic retrograde cholangiopancreatography (ERCP), breath tests, and manometry are regarded as aerosol-generating procedures. Aerosolization of viral particles can occur during the insertion of an endoscope into the pharynx and during the insertion/removal of accessories through the biopsy channel. Though aerosolization has not been confirmed during lower GI procedures, there is a worrisome risk due to shedding of virus in feces even in asymptomatic patients and those without diarrhea. A proportion of patients who come for endoscopy may be asymptomatic or have mild symptoms and this underscores the need for adequate precautions while performing endoscopy. Infection to health care workers is more likely to occur in the early stages of the epidemic due to inadequate precautions and insufficient protection. PPE is an integral part of the preventive measures of transmission of COVID-19 to health care workers.

\section{Practice of Safe Endoscopy in COVID-19 Pandemic}

WHO has formulated a pandemic alert system with six phases (1-6). As per this system, COVID-19 is in phase 6 of the pandemic. Since community spread has already been

${ }^{*}$ Equal contributions by both authors.

DOI https://doi.org/

10.1055/s-0040-1712344

ISSN 0976-5042.
(C)2020 Society of Gastrointestinal Endoscopy of India
License terms

()(1) $\Theta \circledast$ 
established in many countries, the role of prescreening stratification for endoscopy is questionable. In such a situation, it is prudent to consider all patients undergoing endoscopy as a source of potential infection. ${ }^{3}$ The Centers for Disease Control and Prevention (CDC) has designed Biological Safety Levels (BSL) ranked 1 to 4 , based on agents or organisms researched or worked on in any hospital/laboratory setting. Constraints and barriers are set according to the BSL level as a control measure for the containment of microbes and biological agents. In the present COVID-19 pandemic, a level 3 safety (BSL 3 ) is advisable for all endoscopic procedures. ${ }^{4}$ As per BSL 3 requirements, endoscopy should be performed in isolation rooms with all biosafety requirements including standard PPE. ${ }^{5}$ WHO has published guidelines on the use of PPE in COVID-19 and has recommended the use of a respirator, impermeable gown, gloves, and eye protection in aerosol-generating procedures like endoscopy. ${ }^{6}$

Recent guidelines given by major gastroenterology societies in India encourage dividing endoscopic procedures into three categories and only emergency and urgent procedures are to be considered until the COVID-19 threat is over. ${ }^{7}$ In a situation like COVID-19 pandemic with many asymptomatic carriers and reported community spread in various geographical regions around the world, it is recommendable to use PPE while doing all endoscopy-related procedures. In areas where community spread is ruled out through aggressive population-based testing protocols, a risk-based PPE use strategy (-Table 1) may be considered during endoscopy. ${ }^{8}$ Evolution of novel and more sensitive rapid tests can effectively rule out COVID-19 infection before endoscopy in suspected cases and asymptomatic carriers.
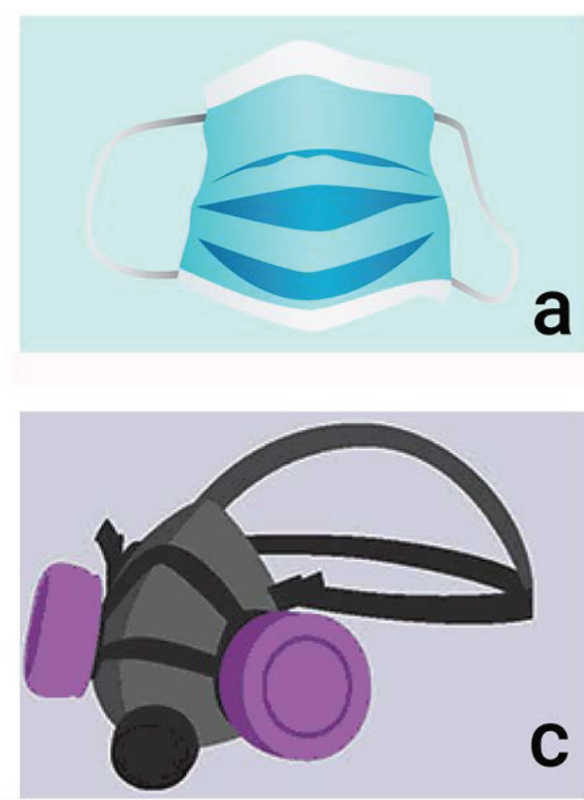

Table 1 Risk stratification for COVID-19 prior to endoscopy ${ }^{8}$

\begin{tabular}{|c|c|}
\hline Low risk & $\begin{array}{l}\text { - No symptoms (e.g., cough, fever, } \\
\text { breathlessness, diarrhea) } \\
\text { - No contact with someone SARS-COV-2 } \\
\text { positive } \\
\text { - No stay in high-risk area during the } \\
\text { previous } 14 \mathrm{~d}\end{array}$ \\
\hline $\begin{array}{l}\text { Intermediate } \\
\text { risk }\end{array}$ & $\begin{array}{l}\text { - Presence of symptoms with } \\
\text { - No history for contact with someone } \\
\text { SARS-COV-2 positive } \\
\text { - No stay in high-risk area during the } \\
\text { previous } 14 \mathrm{~d} \\
\text { - No symptoms but } \\
\text { - Contact with someone SARS-COV-2 positive } \\
\text { - Stay in high-risk area during the } \\
\text { previous } 14 \mathrm{~d}\end{array}$ \\
\hline High risk & $\begin{array}{l}\text { - All emergency endoscopies without patient } \\
\text { history } \\
\text { - At least one symptom + one of the following: } \\
\text { - Contact with someone SARS-COV-2 positive } \\
\text { - Stay in high-risk area during the } \\
\text { previous } 14 \mathrm{~d}\end{array}$ \\
\hline
\end{tabular}

\section{Components of Personal Protective Equipment in Endoscopy}

The goal of PPE use in endoscopy is to improve personal safety in the endoscopy health care environment. By definition, a PPE is a specialized clothing or equipment worn by an employee for protection against infectious materials. Different components of PPE include the following:

1. Masks: Protect nose and mouth and prevent fluid penetration. It should cover the nose and mouth effectively. The different types of masks ( - Fig. 1 ) available are:
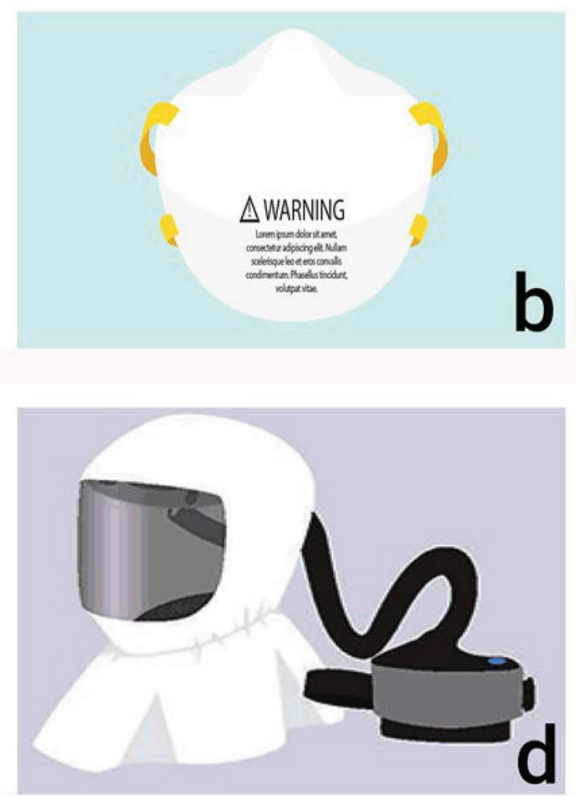

Fig. 1 Types of masks a. Surgical Mask b. N95 Respirator c. Elastomeric Half Facepiece Respirator (EHFR) d. Powered Air-Purifying Respirator (PAPR). (https://www.cdc.gov/coronavirus/2019-ncov/images/hcp/N95-respirator-protection-types-508.jpg). 
a. Surgical masks-Surgical masks block large particles. They are less effective for aerosols less than $5 \mu \mathrm{m}$ in size. They are not respirators and are primarily intended for source control.

b. Filtering facepiece respirators (FFRs; e.g., N95 respirator masks)-"N95" is a term referring to the N95 filter class, which removes at least $95 \%$ of airborne particles when using a "most-penetrating" sized particle during testing. The FFR classes include $\mathrm{N}$ (not resistant to oil), R (somewhat resistant to oil), and $\mathrm{P}$ (strongly resistant to oil) series, which are available at 95, 99, and 100 filtration efficiency levels $^{9}$ (-Table 2). Most N95 masks are disposable (single-use) and not designed for reuse or extended use.

c. Elastomeric respirators-They are tight-fitting respirators made of synthetic or rubber materials. They can be disinfected and reused. These respirators are available as elastomeric half-face respirators (EHFRs) and full-face respirators. A full-face respirator covers eyes also and is not usually used in health care settings.

d. Powered air-purifying respirators (PAPRs)-Reusable respirators that are loose-fitting, hooded, or helmeted. There is a battery-powered blower that forces air through a high-efficiency particulate air (HEPA) filter. It is more efficient in reducing exposures when compared with N95 respirators and EHFRs ( - Fig. 1).

Occupational Safety and Health Administration (OSHA) has established an "assigned protection factor" (APF) as a measure of the efficacy of respirator masks. ${ }^{9}$ Both N95 masks and EHFRs are assigned an APF of 10 which means that both can reduce aerosol concentration by a factor of 10 . APF for PAPRs ranges from 25 to 1,000. The key benefit of EHFRs and PAPRs is the reusability. Both are durable and can withstand multiple sessions of disinfection and cleaning. EHFR offers the benefit of cost saving when taken into consideration the need for routine use for a longer period and shortage of N95 masks during pandemics. One EHFR must be assigned to one health care professional. Key challenges of EHFR include interference with duties, as it may compromise the visual field and speech intelligibility. Furthermore, it needs to be stored in between work shifts and properly cleaned and disinfected. On the other hand, PAPRs have a high APF and there is no need for a fit test. However, there is more interference with duties and the battery needs to be recharged. Cost-wise, EHFR is approximately 40 times costlier than the

Table 2 Classes of filtering facepiece respirators

\begin{tabular}{|l|l|}
\hline N95, N99, N100 & $\begin{array}{l}\text { Filters at least 95\%, 99\%, 99.97\% of airborne } \\
\text { particles. Not resistant to oil }\end{array}$ \\
\hline R95, R99, R100 & $\begin{array}{l}\text { Filters at least 95\%, 99\%, 99.97\% of airborne } \\
\text { particles. Somewhat resistant to oil. }\end{array}$ \\
\hline P95, P99, P100 & $\begin{array}{l}\text { Filters at least 95\%, 99\%, 99.97\% of airborne } \\
\text { particles. Strongly resistant to oil }\end{array}$ \\
\hline
\end{tabular}

N95 mask, while a PAPR is approximately 25 times costlier than EHFR.

2. Gloves: Protect hands. It is made of vinyl, latex, nitrile, etc. Beware of "touch contamination" after wearing. Do not touch one's face or adjust PPE with contaminated gloves. Do not touch environmental surfaces unnecessarily.

3. Gown: Protects skin and/clothing. It can be reusable or disposable. Long-sleeved fluid-impermeable gowns are recommended.

4. Goggles: Protect eyes. It should be snuggly fitting around the eyes. Personal glasses are not a substitute for goggles. Visual clarity may be improved with antifog features.

5. Face shield: Protects face, mouth, nose, and eyes. It should cover the forehead, extent below the chin, and wrap around the sides of the face.

6. Disposable hair cap: Protects hair and ears.

7. Shoe cover: Protects feet/shoes.

\section{Use of Personal Protective Equipment for Safe Endoscopy}

In the absence of widespread reliable and accurate rapid tests for COVID-19, all patients need to be considered as potentially infective and it is recommended that a health care worker performing any upper GI or lower GI procedure should use N95 mask. ${ }^{3}$ In the systematic review and meta-analysis by Offeddu et al, N95 respirators were found to be a better option than surgical masks in protecting health care personnel from SARS. ${ }^{10}$ Chang et al analyzed data from China and found that among health care workers, the greatest risk of exposure to COVID-19 occurs during the early stages of pandemic when tests are unavailable widely. ${ }^{11}$ In the current COVID-19 pandemic where community spread has been documented widely, regardless of the COVID-19 status N95 masks (or equivalents) should be used during endoscopic procedures. As there is documented shedding of virus in fecal samples and possibility of aerosolization during instrument use through biopsy channel, it is wise to extend the use of N95 masks or equivalents in lower GI procedures also.

In the observations during SARS epidemic in 2003 and study conducted by Casanova et al, ${ }^{12}$ a "double-glove" strategy was found to decrease the contamination risk when compared with single-glove strategy. During any endoscopic procedure, irrespective of COVID-19 status, a "doubleglove" strategy should be practiced as part of PPE. The second (outer) pair of glove has to be one size larger than the first pair. ${ }^{3}$ In low risk cases or screening test negative patients, adoption of minimum components of PPE (Surgical mask, Blue isolation gown, and Gloves) during endoscopy should depend on the local health policies, resources, and hospital infection control protocol.

\section{How to Put on PPE (Donning)}

Graphic instructions regarding the steps of using PPE are available at the CDC Web site (https://www.cdc.gov/hai/pdfs/ ppe/ppe-sequence.pdf). The correct order of wearing PPE is as follows (-Fig. 2). 


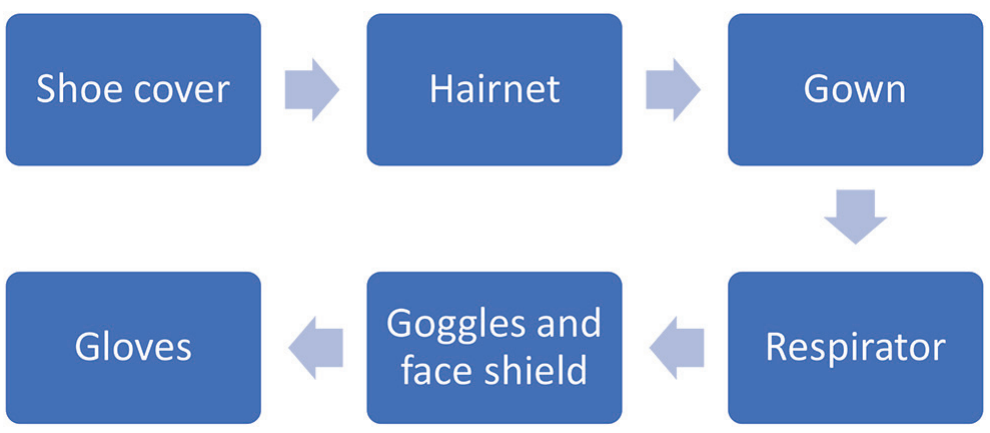

Fig. 2 Sequence of wearing PPE (Donning).
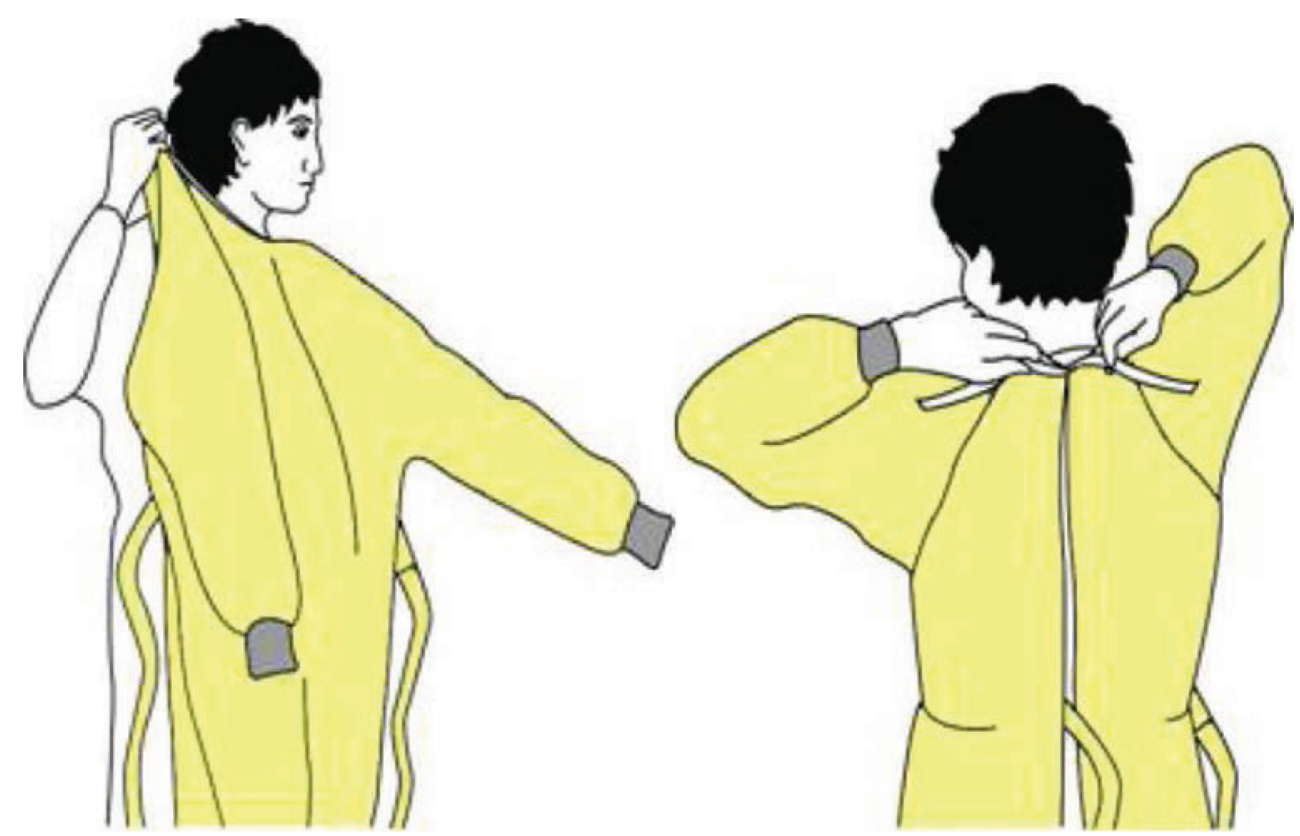

Fig. 3 Donning of Gown.

Gown: Select appropriate size for the gown. Remember that the opening is at the back and secure it at the neck and waist. If gown is too small, use two gowns: tie Gown no. 1 in front and Gown no. 2 in back (-Fig. 3) (https://www. cdc.gov/hai/prevent/ppe.html).

Respirator: Place the respirator over nose, mouth, and chin. Fit flexible nose piece over nose bridge. Secure on head with ties. Perform a fit check: Inhale $\rightarrow$ respirator should collapse; exhale $\rightarrow$ check for leakage around face (-Fig. 4).

Goggles and face shield: Position goggles over eyes and secure to head using ear pieces or head band. Position face shield over face and secure on brow with headband (-Fig. 5).

Gloves: Use two pairs of gloves of correct size. Extend the second pair (outer) of gloves over isolation gown cuffs (-Fig. 6).

\section{How to Take Off PPE (Doffing)}

The correct order of removal of PPE is as follows (- Fig. 7): (https://www.cdc.gov/hai/pdfs/ppe/ppesequence.pdf).

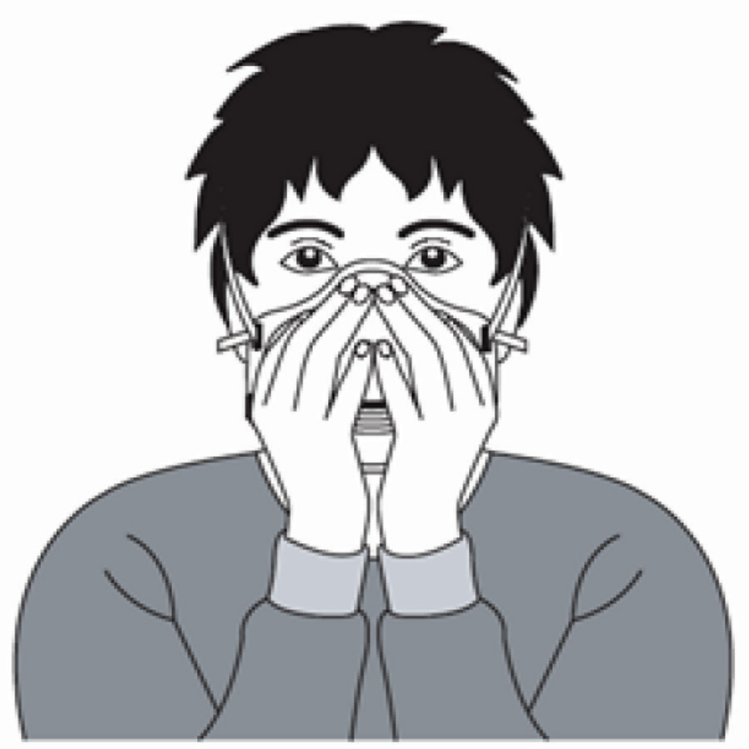

Fig. 4 Donning of Respirator. 

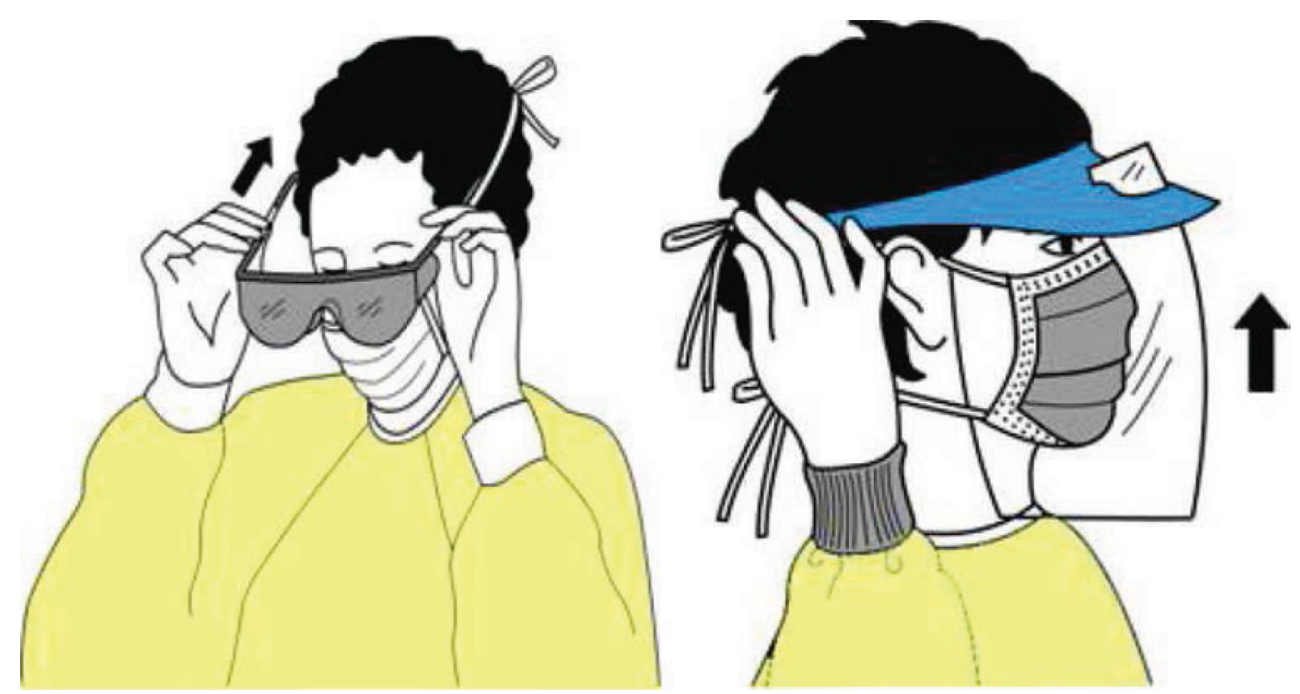

Fig. 5 Donning of Goggles and Face shield.

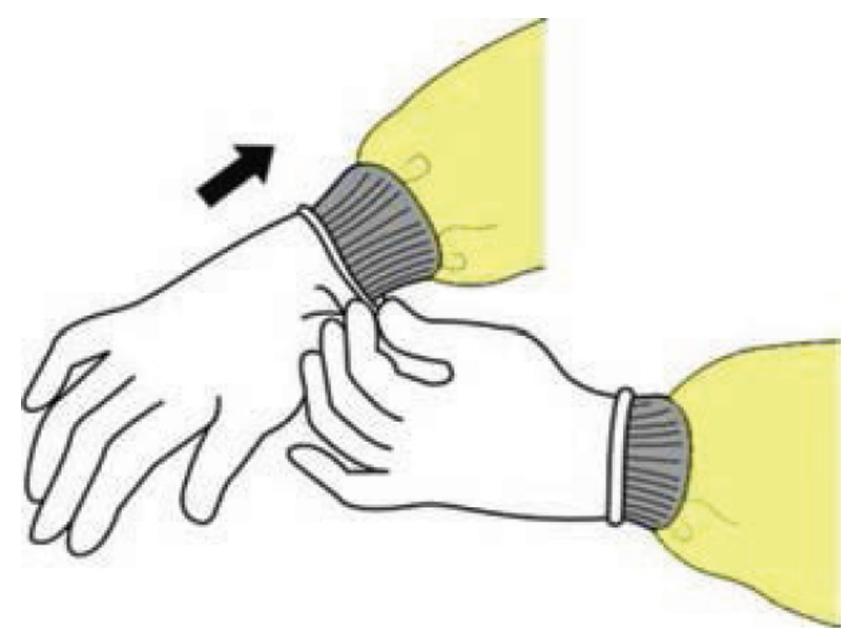

Fig. 6 Donning of Gloves.

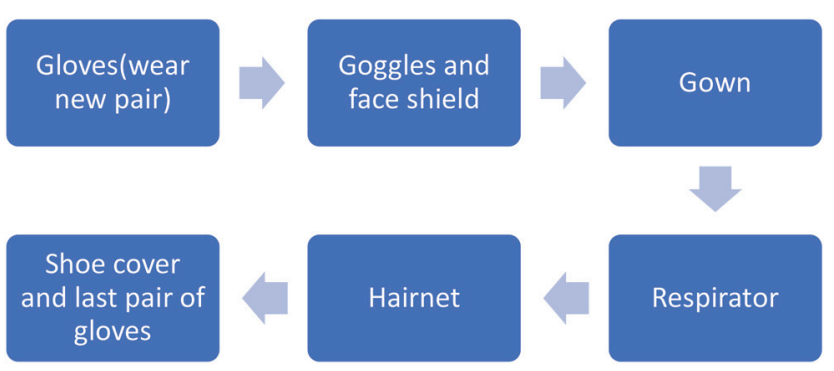

Fig. 7 Sequence of removal of PPE (Doffing).

Gloves: Grasp outside edge near wrist and peel away from hand, turning glove inside-out. Hold in opposite gloved hand. Slide ungloved finger under the wrist of the remaining glove and peel off from inside, creating a bag for both gloves. Use of alcohol-based hand sanitizer should be considered before removing the gloves. Perform hand hygiene again after the gloves are removed. Now wear a new pair of gloves and remove the goggles and face shield (-Fig. 8).
Goggles and face shield: Grasp ear or head pieces and lift away from face. Place them in designated receptacle for reprocessing or disposal (-Fig. 9).

Gown: Unfasten ties (take a second operator's help in gowns with back closures). Peel gown away from neck and shoulder. Turn contaminated outside toward the inside, roll into a bundle and discard (-Fig. 10).

Respirator: Lift the bottom elastic over the head first, then lift off the top elastic and discard ( - Fig. 11).

The last PPE to be removed is the latest pair of gloves. Hand hygiene should be repeated after this. ${ }^{8}$

Learning techniques and steps of using PPE should be available to endoscopy staff by graphic instructions, pictures, and/or video presentations. Both donning and doffing areas should be provided with visual instructions.

\section{Extended Use and Limited Reuse of N95 Respirators}

By definition, "Extended use" refers to prolonged use of the same N95 respirator during encounters with several patients without removing the respirator between patient encounters. On the other hand, "Reuse" refers to the practice of using the same N95 respirator for multiple encounters with patients but removing it ("doffing") after each encounter. ${ }^{13}$ In extreme resource-constrained settings, extended use/reuse of N95 masks can be entertained as part of other PPE. There are limited data in this regard to COVID-19 infection. Some researchers advocate rotating through a series of masks, giving worn masks time to "rest" so that they become virus-free passively. A cleanable face shield or surgical mask over N95 respirator to reduce contamination was recommended by CDC during the H1N1 pandemic. ${ }^{14}$ To increase the viability of N95 masks and at the same time reduce contact transmission, health care workers inside endoscopy suite should follow healthy practices ${ }^{13}$ (-Table 3 ).

The decision regarding reuse or extended use of respirators should be implemented under the hospital infection 

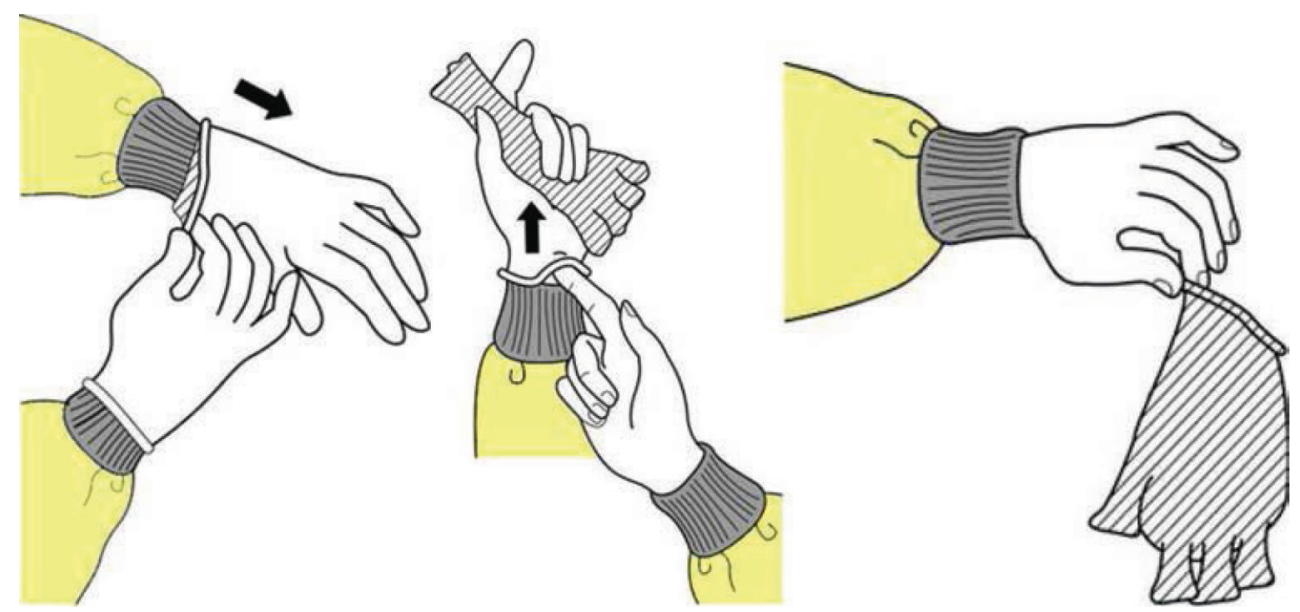

Fig. 8 Doffing of Gloves.
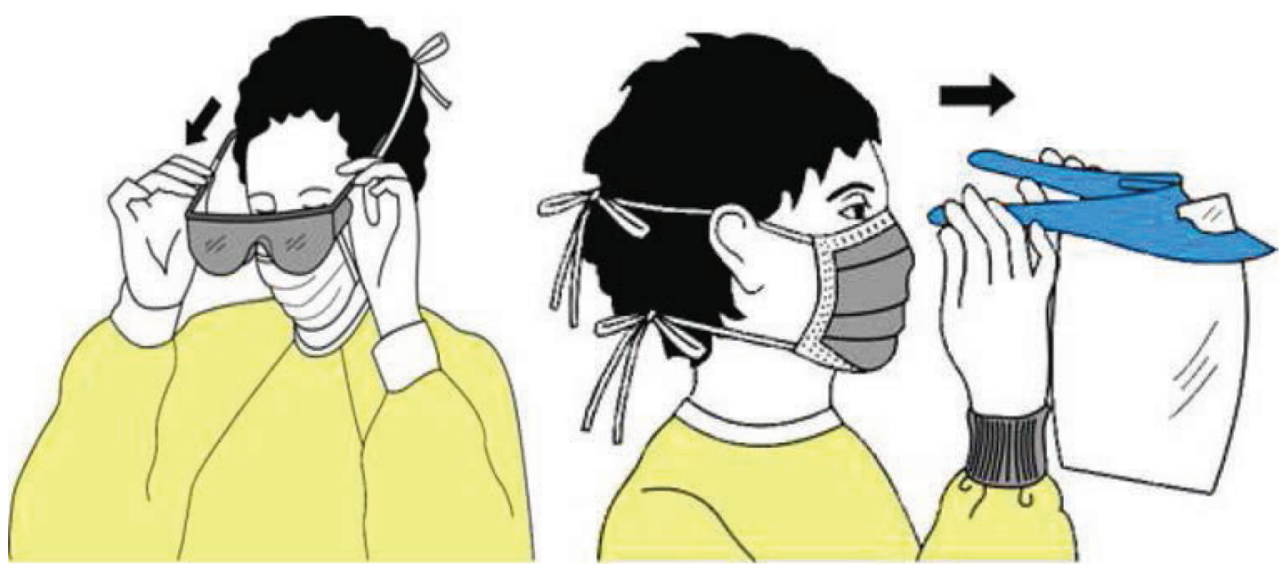

Fig. 9 Doffing of Goggles and Face shield.
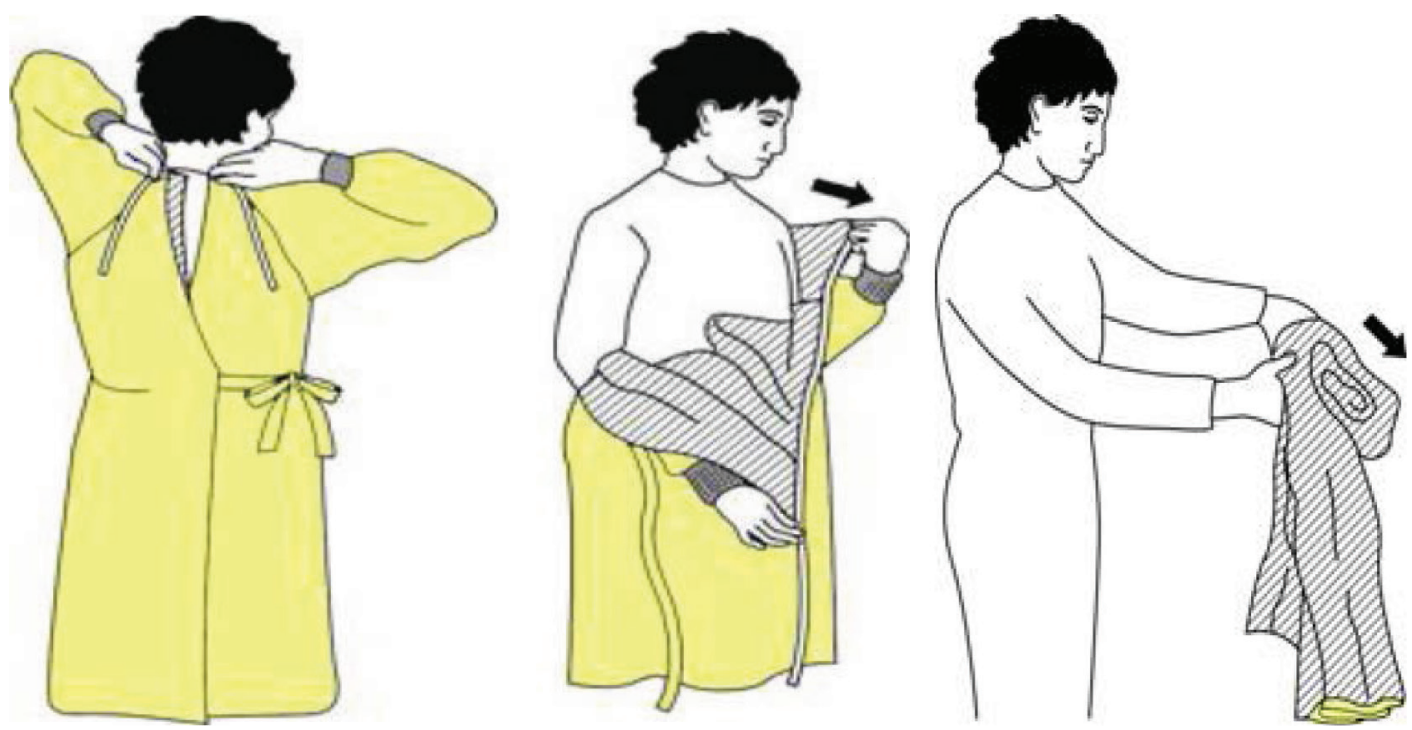

Fig. 10 Doffing of Gown.

control policies with inputs from local health departments. Wherever feasible, extended use is favored over reuse if the respirator maintains its fit and function. Limited indirect evidence suggests that respirators can be recommended for an extended period of not more than 8 hours. It is very difficult to determine the maximum number of safe reuses for an $\mathrm{N} 95$ respirator. In the absence of robust data, it is recommended to limit the number of reuses to no 


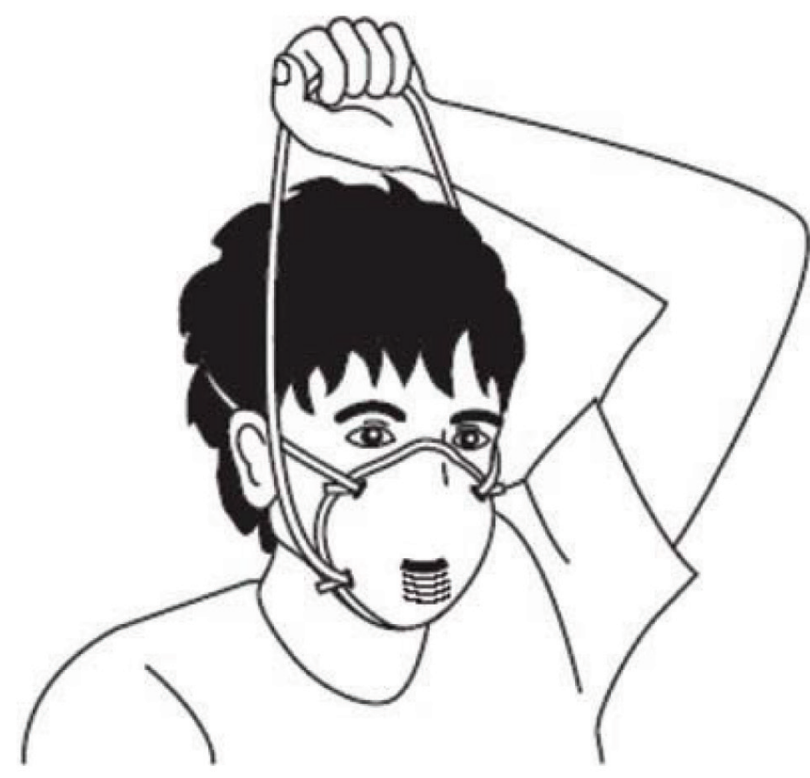

Fig. 11 Doffing of Respirator.

Table 3 Use of N95 mask - Safety tips to reduce contact transmission

- Discard contaminated N95 respirators

- Discard N95 respirators following close contact with a COVID-19 patient

- Consider use of cleanable face shield over an N95 respirator

- Perform hand hygiene before and after touching or adjusting the respirator

- Avoid touching the inside of the respirator

- Hang the used respirators in a designated storage area or keep in a clean, breathable container in between uses

more than 5 uses. ${ }^{15,16}$ In the case of reuse, the N95 respirator should not be shared and must be stored in labeled containers.

Each person in an endoscopy suite should follow safety precautions and has the responsibility to reduce the chances of disease spread to other health care workers and patients $(\text { - Table 4). })^{3,5}$

\section{Conclusions}

Health care workers in the endoscopy suite worldwide could be exposed to significant infection risk due to the current COVID-19 pandemic. Most of the GI endoscopic procedures are regarded as aerosol-generating procedures. Judicious listing of endoscopic procedures with the adoption of enhanced safety measures can prevent transmission of COVID-19 in the endoscopy suite. In this period of the viral pandemic with multiple reports of community spread and high infectivity even among asymptomatic carriers, PPE use is recommendable in all endoscopic procedures irrespective of their COVID-19 status. For low-risk cases from areas with no evidence of community spread, the policy of PPE in endoscopy should be done in accordance with institutional infection control protocol. Health care workers, who properly adhere
Table 4 Safety precautions in endoscopy practice

- Review and be observed the practice of PPE don and doff

- Do not take personal belongings (like phones, stethoscopes, etc.) into any procedural area

- Minimize the number of personnel in the room during the endoscopic procedure

- Review and determine the appropriateness of trainee involvement in procedures

- Avoid personnel switches during the procedure

- Consider nursing teams who follow patient from preprocedure area to procedure room and to the recovery room

- Consider compartmentalization through teams that remain together for the entire day

- Nonprocedural personnel should avoid entering any procedure room after the patient has entered

- Health care personnel in clean area can complete the procedure report

Abbreviation: PPE, personal protective equipment.

to safe donning and doffing of PPE, significantly decrease the spread of this highly transmissible viral infection. Additional training and poster reminders inside the endoscopy suite may reinforce strict adherence to the successful use of PPE. Enhanced safety precautions with very rigorous enforcement can prevent transmission of COVID-19 to health care workers.

\section{Conflict of Interest}

None declared.

\section{References}

1 Symptoms of Coronavirus (COVID-19). Available at: https:// www.cdc.gov/coronavirus/2019-ncov/index.html. Accessed April 27, 2020

2 Wang D, Hu B, Hu C, et al. Clinical characteristics of 138 hospitalized patients with 2019 novel corona virus-infected pneumonia in Wuhan, China JAMA. 2020;323:1061-1069. doi:10.1001/jama.2020.1585

3 Sultan S, Lim JK, Altayar O, et al; AGA. AGA Institute Rapid Recommendations for gastrointestinal procedures during the COVID-19 pandemic. Gastroenterology 2020;doi10.1053/ j.gastro.2020.03.072[Epub ahead of print]

4 Zhang Y, Zhang X, Liu L, Wang H, Zhao Q. Suggestions for infection prevention and control in digestive endoscopy during current 2019-nCoV pneumonia outbreak in Wuhan, Hubei province, China. Endoscopy 2020;52(4):312-314

5 Soetikno R, Teoh AY, Kaltenbach T, et al. Considerations in performing endoscopy during the COVID-19 pandemic. Gastrointest Endosc 2020;doi10.1016/j.gie.2020.03.3758[Epub ahead of print]

6 World Health Organization. Rational use of personal protective equipment for coronavirus disease (COVID-19): Interim Guidance, 27 February 2020. Geneva: World Health organization; 2020. Available at: https://extranet.who.int/iris/ restricted/handle/10665/331215. Accessed April 27, 2020

7 Philip, et al. Joint Guidance from SGEI, ISG and INASL for Gastroenterologists and Gastrointestinal Endoscopists on the Prevention, Care, and Management of Patients With COVID19. Journal of Clinical and Experimental Hepatology, https:// doi.org/10.1016/j.jceh.2020.04.001

8 Repici A, Maselli R, Colombo M, et al. Coronavirus (COVID-19) outbreak: what the department of endoscopy should know. 
Gastrointest Endosc 2020;doi10.1016/j.gie.2020.03.019[Epub ahead of print]

9 A Guide to Air-Purifying Respirators. Publication No. 2018176; August 2018. Available at: https://doi.org/10.26616/ NIOSHPUB2018176 DHHS (NIOSH). Accessed April 27, 2020

10 Offeddu V, Yung CF, Low MSF, Tam CC. Effectiveness of masks and respirators against respiratory infections in healthcare workers: a systematic review and meta-analysis. Clin Infect Dis 2017;65(11):1934-1942

11 Chang D, Xu H, Rebaza A, Sharma L, Dela Cruz CS. Protecting health-care workers from subclinical coronavirus infection. Lancet Respir Med 2020;8(3):e13

12 Casanova L, Alfano-Sobsey E, Rutala WA, Weber DJ, Sobsey M. Virus transfer from personal protective equipment to healthcare employees' skin and clothing. Emerg Infect Dis 2008;14(8): 1291-1293
13 Recommended Guidance for Extended Use and Limited Reuse of N95 Filtering Facepiece Respirators in Healthcare Settings. Available at: cdc.gov/niosh/topics/hcw controls/recommended guidance extuse.html. Accessed April 27, 2020

14 Bailar J, Burke D, Reusability of Facemasks during an Influenza Pandemic. Washington, DC: Institute of Medicine of the National Academies; 2006

15 Fisher EM, Shaffer RE. Considerations for recommending extended use and limited reuse of filtering facepiece respirators in healthcare settings. J Occup Environ Hyg 2014;11(8): D115-D128

16 Bergman MS, Viscusi DJ, Zhuang Z, Palmiero AJ, Powell JB, Shaffer RE. Impact of multiple consecutive donnings on filtering facepiece respirator fit. Am J Infect Control 2012;40(4): $375-380$ 